\title{
Ava Moodle, Implantação, Importância e Dificuldade de Aplicação como Extensão ao Ensino Tradicional na visão do Professor
}

\section{Ava Moodle, it's implementation, Importance and Difficulty to Support Traditional Extension in the Teacher's view}

LUCAS PLAUTZ PRESTES Universidade Federal do Rio Grande do Sul

ANDREIA SOLANGE BOS Instituto Federal do Rio Grande do Sul

PAULA R. CASTRO Pontificia Universidade Católica do Rio Grande do Sul

RAFAEL BONETI Pontificia Universidade Católica do Rio Grande do Sul

MILTON ANTÔNIO ZARO Universidade Federal do Rio Grande do Sul 
Resumo: A partir da evolução do Ensino a Distância (EaD) no Brasil, pode-se afirmar que tal prática se encontra consolidada no ensino superior. Apesar desta afirmativa, pouco se relata na estrutura básica de ensino.O trabalho objetiva realizar um estudo de caso na aplicação do ensino EaD de forma complementar ao ensino básico tradicional. A pesquisa abrange as dificuldades que envolvem a aplicabilidade ao corpo docente, demonstrando que a inserção da forma de ensino híbrida complementar na educação, aplicada de forma gradual, não obrigatória e com suporte conciso da área técnica, propiciou uma forte ligação entre a instituição, o professor e o aluno por meio do ambiente virtual de aprendizagem. Esta união, fez com que o aluno se tornasse o protagonista da construção do seu conhecimento e não mais um simples espectador, havendo a integração de diferentes perspectivas educacionais entre a instituição de ensino tradicional e o aluno com DNA digital.

Palavras-chave: Ambiente Virtual de Aprendizagem (AVA). Moodle. Estudo de Caso. Ensino Fundamental e Médio. Aluno Digital.

Abstract: From the evolution of distance education (EaD) in Brazil it's possible say that this practice is consolidated in higher education. Despite this assertion, little is said about the basic structure of teaching. Therefore, the objective of this study is to carry out the case study in the application of distance education (EAD), in a complementary way to traditional basic education. The research encompasses the difficulties involved in its applicability to the teaching staff, demonstrating that the insertion of the complementary hybrid teaching method in education, applied in a gradual, non-compulsory way and with concise support of the technical area, provided a strong link between the institution, the teacher and the student through the virtual learning environment. This union made the student to become the protagonist of the construction of his own knowledge and no longer a mere spectator, with the integration of different educational perspectives between the traditional teaching institution and the student with digital DNA.

Keywords: Virtual Learning Environment (AVA). Moodle. Case study. Elementary and high school. Digital Student. 


\section{Introdução}

O Brasil é um país com extensa área territorial e grandes diferenças culturais em seus diversos estados. A sua extensão territorial e sua diversidade cultural são desafios na popularização e controle de qualidade do ensino brasileiro. As distâncias entre o aluno e a escola, juntamente com a dificuldade de locomoção, tornam-se para o aluno um desafio diário na construção do seu conhecimento.

O país, a partir de 2003, iniciou-se um pacote de incentivos de bolsas para famílias de baixa renda, com o objetivo não somente de retirar a classe baixa da extrema pobreza, mas também estimular as condições mínimas para a educação. As famílias para se beneficiarem de tal incentivo, devem obrigatoriamente garantir a frequência dos seus filhos nas escolas brasileiras.

O sistema de bolsas e pacotes de incentivos para a classe baixa está sendo gradativamente ampliado, possibilitando não somente o acesso da classe menos favorecida à escola, mas ainda tornando a informação acessível a um maior número de brasileiros. Esse pacote de incentivos está além da simples obtenção de bolsas para a extrema pobreza, mas ampliado em forma de incentivos que estende-se desde a moradia até o acesso à educação superior para as classes $C$ e $D$ da população. Com o objetivo de levar internet a todas as casas brasileiras, a partir de um acordo entre o governo federal, as empresas de telefonia e as prefeituras, foi dado início ao "Projeto Internet para Todos".

Segundo a jornalista Brito (2018), o governo federal ampliou o programa "internet para todos" com a possibilidade de disponibilizar conexão em áreas de difícil acesso por meio do novo Satélite Geoestacionário de Defesa e Comunicações Estratégicas (SGDC), lançado em 2017, no qual recebeu 3 bilhões em investimentos para sua implementação.

Esse Projeto tinha como objetivo fornecer internet com custo acessível para a população de baixa renda, pois a mesma é uma fonte essencial de acesso à informação que pode fomentar a construção de novos saberes em sinergia com as informações internacionais, tornando-se uma espécie de biblioteca de âmbito mundial. Após disponibilizar internet nas escolas e facilitar o acesso às casas brasileiras, o governo ganhou um novo desafio, o de tornar possível a utilização de tais meios de comunicação nas escolas públicas em todo o país, aproximando essa importante ferramenta deste novo perfil da população, o chamado aluno digital.

De acordo com Garcia e Bizzo (2013), a utilização da EaD na modalidade de formação continuada a professores pode ser motivada tanto para os professores-cursistas quanto para tutores. No entanto, ela difere em comparação com a presencial devido as suas diferenças tecnologias aplicadas no ensino. Neste sentido, em sua investigação listam as dificuldades encontradas pelos professores-cursistas no decorrer do curso. Tais contratempos referem-se às tecnologias; aos conteúdos; às questões didático pedagógicas e questões culturais, diante da aplicação da tecnologia no processo do ensino e aprendizagem.

Moore (1993) desenvolveu o conceito de $\mathrm{EaD}$ que está relacionado com a Teoria da Distância Transacional. Nessa perspectiva, percebe-se o fomento da chamada EaD (Educação a Distância) que é baseada no construcionismo ${ }^{1}$ com ênfase na interatividade virtual, promovendo o trabalho colaborativo calcado na vontade dos indivíduos envolvidos e, sobretudo, na interação aprendiz-computador-professor-aprendiz ${ }^{2}$, estabelecendo um ciclo que vai evoluindo à medida que se dá a construção do conhecimento. Para tanto, os cursos ofertados via rede podem utilizar ambientes de suporte para a Educação a Distância, os quais constituem um espaço virtual estruturado, visando facilitar as interações por meio de diferentes ferramentas: chats, fóruns ou grupos de discussão, correios, portfólios, entre outras.

Portanto, esta pesquisa procurou refletir sobre o uso das Novas Tecnologias de Informação e Comunicação (NTICs), mais especificamente na construção do método de aplicação do

${ }^{1}$ Cf. Papert (1994) O termo Construcionismo, no uso educacional contemporâneo em geral, remete à doutrina de Piaget enfatizando que o conhecimento não pode simplesmente ser transmitido ou transferido pronto para uma pessoa.

20 ciclo proposto não difere daqueles que explicam o processo de aprendizagem em praticamente todas as teorias interacionistas formuladas por diversos autores, tais como, Piaget (1976), Vygotsky (2000), Wallon (1989). 
ambiente virtual de aprendizagem Moodle em uma instituição de Ensino federal em Porto Alegre, procurando identificar se há inovação, ruptura ou conservação do status quo. Insere-se em uma preocupação de explicitar os pressupostos pedagógicos que fundamentam esta ação. A partir da evolução consolidada do ensino EaD no Brasil, a pesquisa realiza a análise do estudo de caso no processo de construção do ambiente virtual Moodle de forma eficiente e eficaz em uma escola de ensino federal tradicionalista em Porto Alegre. A pesquisa visa realizar uma análise das dificuldades que envolvem a sua aplicabilidade, bem como o incentivo ao corpo docente em sua utilização, visando melhores práticas educacionais.

\section{Contexto do Estudo}

Atualmente, vive-se em um mundo de constantes e contínuas transformações em uma acelerada evolução das tecnologias de informação e comunicação, com os espaços de interação humana imensamente ampliados. Isso, por sua vez, potencializa os espaços educativos. Entre as possibilidades acima citadas, tem-se a Comunicação Mediada por Computador - CMC, que pode ocorrer de forma assíncrona (correio eletrônico, lista de discussão, fórum) e de forma síncrona (chat, teleconferência, etc.). Porém, para garantir um ambiente que proporcione real aprendizagem e desenvolvimento dos sujeitos aprendentes, não basta apenas implementar a tecnologia no sistema educacional.

Vive-se na era digital, onde o Ambiente Virtual de Aprendizagem AVA se torna necessário no processo de ensino e aprendizagem. Pelo ponto de vista pedagógico é muito importante que haja a interação entre o professor e aluno na construção e desenvolvimento da aprendizagem. Desta forma, o AVA deve proporcionar essa troca de informação, para mostrar ao professor o desenvolvimento do processo de aprendizagem do estudante. Segundo Vygotsky (1998), este acompanhamento refere-se a Zona de Desenvolvimento Proximal (ZDP) do aluno, onde entende-se o espaço entre $o$ aluno ter habilidade em resolver sozinho a atividade e o espaço onde precisa do auxilio do professor. Desta forma, o estudante evolui em habilidades e amplia a Zona de Desenvolvimento Proximal.

Para Mozzaquatro e Medina (2008), o processo de avaliar o Ambiente Virtual de Aprendizagem (AVA) é uma função árdua, pois está em constante transformação e desenvolvimento. A análise do Ambiente Virtual é um tema que vem sendo debatido pelos autores da área da educação, principalmente pelos especialistas em informática na educação, pela relevância que esta ferramenta tem como recurso nas práticas educacionais.

A demanda da formação sofre uma transformação qualitativa de pensar e agir e não pode perder a perspectiva de ser uma prática social humanizadora. O uso das NTIC precisa ser inserido nesse contexto como um meio para ampliar o processo de construção do conhecimento e não como um fim em si mesmo.

Lévy (2000) faz referência que, com o advento do computador, ocorre a mudança da relação entre gerações, entre sistemas de ensino e com o conhecimento. Há um verdadeiro universo semântico dentro de comunidades virtuais, pessoas que pensam juntas e são interdependentes. Assim, vê os professores sendo orientadores do processo de aprendizagem de seus alunos, bem como pesquisadores e interlocutores em um ciberespaço que contemple uma comunidade mais ampla de conhecimento.

Avaliar a qualidade do ambiente virtual de aprendizagem é, segundo Carvalho Neto (2011), a análise da qualidade deste espaço que perpassa por informações que contém no ambiente e pela usabilidade e funcionalidade do sistema. Segundo o autor o estudo da qualidade do AVA deve ser dividido em dois grupos pela ótica da funcionalidade. O primeiro grupo está relacionado ao desempenho do próprio sistema porém o outro grupo refere-se aos aspectos gerais da usabilidade, ou seja, da forma como o usuário se relaciona com o sistema.

Como isso se processa no real? Em que medida os professores deixam de ser especialistas "difusores de conhecimento" para serem incentivadores, animadores de uma "comunidade coletiva"? Ainda estamos em um paradigma de cursos de formação para professores nos quais 
as disciplinas acontecem de forma isolada, tendo apenas um vínculo linear e não uma compreensão inter ou transdisciplinar, ou mesmo de "comunidades virtuais".

É preciso, ainda, o cuidado de perceber e revelar a cultura e a ideologia que se insere no processo de inclusão das tecnologias no ambiente educativo, indicando as possibilidades e os limites concretos das teorias da computação. Assim, não podemos mais conceber uma educação à margem da tecnologia, mas seu uso deve ser pedagogicamente reconstruído e assumido coletivamente pelo conjunto dos professores. É o uso didático-pedagógico que se faz do instrumento que define a forma do processo do ensinar e do aprender e não o instrumento em si.

A construção do conhecimento não pode ser entendida como individual, é necessário que o professor se conscientize de que seu papel é o de mediador no processo de aprendizagem, aberto às novas experiências e a entender os problemas de seus alunos e tentar levá-los à auto realização. Conforme FREIRE (2002) "o educador democrático não pode negar-se o dever de, na sua prática docente, reforçar a capacidade crítica do educando, sua curiosidade, sua insubmissão". (FREIRE, 2002, p.13)

Freire (2000) chama a atenção para os desafios da educação frente à nova reestruturação tecnológica, reforçando sua visão de a educação ser um ato criador e da necessidade do educando ser sujeito, compreender o mundo e nele intervir. Insiste que toda intervenção pedagógica traduz uma concepção de uma determinada teoria do conhecimento e da forma política do sujeito que a exerce, salientando a necessidade da postura crítica da subjetividade no processo de conhecimento. Logo, a partir deste cenário que ele se refere à tecnologia. Apesar da globalização econômica e o avanço da tecnologia estarem sendo apontados como perfiladores de um amanhã dado como certo, precisamos questioná-los e, pela constatação crítica e rigorosa dos fatos, necessitamos intervir no processo. A exigência de saber que "mudar é difícil, mas não impossível" (FREIRE, 2011, p.36), sempre foram marcas da prática educativa e as inovações tecnológicas também sublinham essa necessidade.

No contexto de AVA, Bassani e Behar (2006, p. 01) comentam que nesses espaços tem-se a possibilidade do acompanhamento da frequência e da produção de cada aluno, uma vez que os ambientes possuem uma base de dados que armazena e pode armazenar a frequência e assiduidade a cada um dos recursos disponíveis no ambiente. Segundo as autoras, o enfoque quantitativo da interação faz referência ao que é possível apresentar de informações quantificáveis, como número de acessos ao ambiente, número de acessos a determinadas atividades, quantidade de trabalhos enviados ou ainda o número de contribuições em determinada ferramenta (BASSANI; BEHAR, 2006, p. 02 -03).

É necessário mudar a perspectiva de vista dos sujeitos que participam no espaço virtual de aprendizagem com a interação. Porém esse processo é gradativo, com algumas atitudes dos estudantes com relação aos recursos e a autonomia.

\section{Learning Management Systems (Sistema de Gestão de Aprendizagem)}

Diversos conceitos na atualidade foram criados e remodelados com a Internet. Expressões como e-commerce, e-business, e-book e e-mail fazem parte do cotidiano das corporações. A esses está se juntando o termo e-learning que tem como meta prover a educação institucional de uma série de facilidades quando em conjunto com certa infraestrutura tecnológica.

O e-learning também conhecido por Ensino a Distância ou Educação a Distância (EaD), tornou-se uma tendência, contribuindo com os métodos tradicionais de ensino e apresentando alternativas que ensejam economia de recursos e de tempo na produção de conhecimento. Esse necessita integrar atividades em conjunto com as novas tecnologias de informação e comunicação, de modo que essas sirvam como ferramentas qualitativas e inovadoras, e que tenham a capacidade de instrumentalizar alunos e professores para o desenvolvimento de novas possibilidades de trabalho. 


\subsection{Ciclo de Aprendizagem e Software Educativos}

O processo de construção do conhecimento, que acontece na relação do sujeito com outros sujeitos, foi amplamente pesquisado por Jean Piaget que explicou essa construção por intermédio do ciclo Assimilação-Adaptação-Acomodação. Para Papert³ (1980), a importância de enriquecermos os ambientes de aprendizagem onde os sujeitos atuarão e serão capazes de construir os conceitos e ideias reside na qualidade dos conhecimentos lá construídos que impregnam esses ambientes. Apresentou ainda o termo que é muito utilizado na construção do conhecimento, sob a influência das novas tecnologias de informação e comunicação, denominado construcionismo. Esse é gerado sobre a suposição de que os aprendizes farão melhor descobrindo por si mesmos o conhecimento específico de que necessitam.

O construcionismo também possui a conotação de conjunto de construção incluindo linguagens de programação a partir dos quais programas podem ser construídos um poema, um castelo de areia. Modelos e formas matemáticas podem ser construídos bem como uma teoria do universo, entre outros. Papert (1994, p. 127) define como característica basilar do construcionismo "[...] o fato de que examina mais de perto do que outros ismos educacionais a ideia da construção mental".

Quando se utiliza softwares abertos, Valente (1993) refere-se que, na interação aprendiz computador é estabelecido um ciclo, a saber: Descrição-Execução-Reflexão-Depuração (DERD nd). O ciclo DERD - nd que se estabelece na interação com o computador pode ser mais efetivo se mediado por um professor que saiba o significado do processo de aprender por intermédio da construção do conhecimento. Assim, a EaD é baseada no construcionismo com ênfase na interatividade virtual, no trabalho colaborativo, na vontade dos sujeitos envolvidos e na interação aprendiz-computador-docente-aprendiz $(A B C D)$, formando um ciclo que evolui à medida que se constrói o conhecimento.

O ciclo da aprendizagem na interação aprendiz-computador aqui explicitado pode ser observado, principalmente, na situação em que o aprendiz utiliza o computador com softwares específicos para resolver um determinado problema ou construir algo de seu interesse particular ou do interesse de uma comunidade, mas de forma cooperativa. Os ciclos acima definidos não são diferentes daqueles que explicam o processo de aprendizagem em praticamente todas as teorias interacionistas.

O ensino dessa forma pode utilizar ambientes de suporte para Educação a Distância, os quais constituem um espaço virtual organizado que pode facilitar as interações por meio de Chat, Fórum ou Grupo de Discussão, Correio, Portfólio e outras. Por outro lado, a bibliografia especializada enfatiza que o computador é uma ferramenta adequada para proporcionar a construção do conhecimento mediante a utilização de softwares educativos abertos, software aplicativo na educação ou com software utilitário para educação.

\subsection{Ambiente Virtual de Aprendizagem - AVA}

Os ambientes virtuais de aprendizagem, conhecidos como AVA, são ferramentas que possuem o objetivo de auxiliar a construção de cursos ou treinamentos com a utilização da web. Logo, essas ferramentas pretendem auxiliar o professor a gerenciar o conteúdo a ser disponibilizado aos alunos, bem como fomentar o controle de acessos e conteúdo de seus alunos ao sistema. O AVA será de suma importância para a construção do conhecimento do aluno mediante ao novo desafio proposto, maior colaboração entre aluno e professor, tornando assim o professor cada vez mais presente no processo de ensino e de aprendizagem junto ao aluno.

Novas abordagens surgem pela utilização crescente de multimídia e ferramentas de interação a distância no processo de produção de cursos.

${ }^{3}$ Pesquisador Sul Africano, que trabalhou com Piaget. 
Devido ao avanço das mídias digitais e da expansão da Internet, torna-se possível o acesso a um grande número de informações, a interação e a colaboração entre pessoas distantes geograficamente ou inseridas em contextos diferenciados. Esta constatação indica a necessidade de desenvolver ações permanentes de inserção de novas tecnologias no processo educativo (MORAN, 2000, p.36).

A EaD é uma possibilidade concreta na promoção da democratização do saber, com seus benefícios que podem ser avaliadores com base em critérios primordialmente técnicos, sociais e econômicos. Os enfoques de aprendizagem aberta e métodos de aprendizagem a distância, exercem impacto sobre o campo educacional, sendo particularmente apropriados ou eficientes e suscitando concepções de geração, transmissão e aquisição de conhecimento. Atualmente existem diversas plataformas disponíveis de AVA tais como: Moodle, SOLAR, TelEduc, entre outras.

\subsubsection{O Moodle}

O Modular Object-Oriented Dynamic Learning Environment (MOODLE), é um sistema de administração de atividades educacionais destinado à criação de comunidades online, em ambientes virtuais voltados para a aprendizagem colaborativa. Permite, de modo simplificado, a um estudante ou a um professor integrar-se, estudando ou lecionando, em um curso online à sua escolha. Seu foco é disponibilizar aos educadores as melhores ferramentas para gerenciar e promover a aprendizagem.

O conceito foi criado em 2001 pelo educador e cientista computacional Martin Dougiamas, sendo que esse ambiente virtual de apoio à aprendizagem possui código aberto, livre e gratuito. O Moodle encontra-se disponível em 75 diferentes línguas e conta com 25.000 websites registrados, em 175 países. O ambiente mantém-se em desenvolvimento por uma comunidade que abrange professores, pesquisadores, administradores de sistema, designers instrucionais, programadores, e usuários de todo o mundo. Evolui constantemente adequandose às necessidades dos seus utilizadores.

De acordo com o M. Schooll (2014), os sistemas de informação online aplicado a diferentes dispositivos estão sendo cada vez mais utilizados em processos de aprendizagem e como parte da educação continuada dentro de uma ampla gama de disciplinas. Nesse caso podemos citar o Moodle por estar presente em diferentes dispositivos como tablets, celulares e computadores. Esta fato ocorre devido que a plataforma pode ser facilmente adaptada a diferentes tecnologias.

O conceito de integração do Moodle a diferentes tecnologias é fortemente orientada na atual forma, ou seja, ele é capaz de gerenciar a administração do ambiente a partir da sua utilização em diferentes plataformas, gerando relatórios aos seus administradores (M. Schooll et. al 2014).

Abaixo está descrito algumas das diversas ferramentas inseridas no Moodle a serem utilizadas no projeto proposto, entre elas são:

- CHAT - Permite a comunicação de modo síncrono entre alunos e professores.

- DIÁRIO - Permite a reflexão e comunicação entre aluno e professor de modo individual, possibilitando assim comentários, feedback de atividades e avaliações.

- QUESTIONÁRIO - Permite a realização de questionários pelo professor com período de disponibilidade pré-definido, feedback automático de respostas bem como sistema de avaliação programável. 
- TAREFA - Permite disponibilizar tarefas a serem realizadas de modo off-line, tais como: redações, relatórios, projetos, imagens etc.

- FORUM - Possibilita a comunicação assíncrona entre seus usuários.

- GLOSSÁRIO - Possibilita a inserção e exibição de palavras com seus respectivos dicionários.

- ENQUETE - Possibilita a criação de enquetes entre os usuários.

- PESQUiSA DE AVALIAÇÃo - Possibilita a criação de uma pesquisa de avaliação.

- WIKI - Ferramenta que possibilita a criação de textos de forma colaborativa entre seus integrantes.

Dentre os ambientes virtuais de aprendizagem disponíveis tratamos mais especificamente do Moodle, por ser um software consolidado e de expressiva aceitação pelos usuários. Esse necessita de uma ergonomia adequada; como aprendiz, não pode dispensar a pedagogia; e, como leitor, necessita da comunicação com o meio que viabiliza a aprendizagem.

\subsection{Alguns Desafios do Docente Frente a EAD}

No contexto do presente trabalho, entende-se que a dificuldade de transposição do ensino presencial para o ensino on-line, engloba todas as dificuldades que o professor do ensino presencial possui para realizar as mudanças técnicas e pedagógicas necessárias para atuar efetivamente no ensino a distância. E essa é uma questão a ser levada em consideração, pois não basta o domínio da ferramenta, mas é necessária uma profunda fundamentação teórica do que é a ferramenta e do como articulá-la quer seja como complemento ao ensino presencial ou como suporte técnico pedagógico para o ensino totalmente a distância.

O processo de conhecimento acontece na mediação realizada entre o sujeito e o objeto, ou seja, na interação entre sujeitos adquire-se o conhecimento sobre o objeto. Dessa forma, dizemos que o outro nos constitui. Para Vygotsky (2007), aprendemos inicialmente na relação com os outros, a partir da participação social e cultural, em relações inter-psicológicas e depois internalizamos o conhecimento, numa relação chamada intra-psicológica (individual). Fora da escola, o sujeito internaliza os conceitos pseudocientíficos e, na escola, ocorre a internalização dos conceitos científicos, através da mediação do professor e de outros alunos mais capacitados.

Diferentemente do que ocorre no ensino presencial, no ensino on-line o professor não tem contato físico com o aluno e nem compartilha o mesmo espaço e tempo. Na EaD o professor normalmente utiliza o AVA para implementar suas práticas educativas e para interagir com os alunos. Nessa modalidade de ensino, o professor deve adotar uma postura ativa e mediadora para que a interação existente no AVA (Moodle, na pesquisa realizada) possa se constituir em construção de conhecimento. Essa postura por parte do professor pode encontrar dificuldade para ser adotada, pois:

O fato de na EAD o ensino ser conduzido por intermédio das NTICs tornam-no um desafio para a maioria dos professores que precisam substituir os modos de interação tradicionais e descobrir o potencial destas tecnologias para o processo de ensino e de aprendizagem, que se dá através do processo de humanização da relação, cujas técnicas variam de acordo com a tecnologia (SANTOS; SILVA, 2009, p.7).

A interação, na atualidade, passa a ser um fator chave no processo educativo, tanto no ensino presencial como no ensino on-line, diante da nova postura do aluno e da possibilidade 
de obtenção da informação e do conhecimento por diversas mídias propiciadas pela sociedade digital.

Diante dessa quebra de paradigma educativo, o professor pode encontrar dificuldade de transpor suas ações educativas do ensino presencial para o ensino virtual, o que pode ser contornado com uma capacitação adequada, ou outro tipo de ação, que leve o professor a um processo de reflexão e redimensionamento de sua ação pedagógica, de forma a poder enfrentar o desafio de educar com o uso das NTICs que permeiam a sociedade contemporânea.

\section{Os Caminhos da Pesquisa}

A definição dos caminhos da investigação é, como todos os outros, um momento especial no processo de pesquisa, necessitando buscar alinhamento com os seus objetivos. Nesse processo, a pesquisa assume uma posição de exploração no sentido em que busca, entre tantos possíveis caminhos, a flexibilidade na composição e na articulação de diferentes perspectivas, conceitos e ideias de investigação articulando conhecimentos de diferentes campos e diferentes áreas.

A dialética é a arte da discussão. Ela não se confunde com a retórica. Enquanto a segunda pretende impressionar e captar, a primeira busca não apenas convencer, mas também levar à compreensão. Assim, compreende o raciocínio que busca a verdade por intermédio da conciliação das contradições do pensamento que ela repassa ao ir da afirmação à negação. Logo, dialética apresentou-se como a melhor opção metodológica para organização desta pesquisa, considerando que o foco deste trabalho era adentrar o âmbito da aplicabilidade do uso das Novas Tecnologias de Informação e Comunicação (NTIC), mais especificamente no AVA - Moodle - a partir da experiência em instituição de Ensino federal.

A pesquisa foi realizada por meio de observação direta, pesquisa bibliográfica institucional e perguntas de respostas livre, aplicada aos professores que fazem o uso do ambiente Moodle como complemento da sala de aula. A realização da análise de documentos institucionais relacionado ao histórico do ambiente escolar, de forma complementar a pesquisa com a equipe de apoio técnico institucional, responsável em aplicar e manter o ambiente e seus respectivos professores foi de fundamental importância para compreender a construção do processo de ensino e ambiente virtual.

\subsection{O Lócus da Pesquisa}

A instituição de Ensino Federal, trata-se de uma Instituição com mais de 100 anos de existência e essencialmente tradicional com cerca de 1100 alunos, sendo que, via de regra, aproximadamente $57 \%$ deles são meninos e $43 \%$ são meninas. O ingresso se dá a partir do 60 Ano do Ensino Fundamental e no $1^{\circ}$ Ano do Ensino Médio, através de concurso público aberto a toda a população. Seu diferencial educacional consiste no fato de possuir uma proposta pedagógica que almeja a educação integral cujo o objetivo é não apenas proporcionar uma sólida base em conteúdos disciplinares, mas também preparar o aluno para a vida cidadã.

A opção por essa instituição se deve ao fato de que ela se destaca por sua organização e busca incessante em unir a tradição ao uso racional das novas tecnologias. Por conseguinte, visamos estudar a aplicabilidade e funcionalidade do ambiente virtual de aprendizagem Modular Object-Oriented Dynamic Learning Environment (MOODLE) -, no contexto da escola, a partir do olhar dos professores e gestores.

\subsection{Estrutura da Pesquisa}

A pesquisa realizada foi de cunho qualitativo no qual os significados e a interpretação surgiram do fenômeno observado no contexto da coleta dos dados para poder abstrair e depreender os conceitos que se deseja. A Pesquisa teve como base preferencial os pressupostos que servem de fundamento para a ação docente e dos gestores no uso do 
ambiente virtual Moodle, refletir como esta se realizava e compreender se havia inovação no uso das NTIC na prática dos sujeitos.

Quadro 1 - Coleta de Dados e Unidade Amostral.

\begin{tabular}{|c|c|}
\hline Técnicas de Coleta de Dados & Unidade Amostral \\
\hline Aplicação do questionário & Professores que utilizam o AVA Moodle. \\
\hline Observação Direta & $\begin{array}{l}\text { Estrutura do processo do software passo-a- } \\
\text { passo, metodologia usada nos processos de } \\
\text { atendimento, ocorrência de problemas, tempo e } \\
\text { tipo de manutenção empregada. Tempo de entrega } \\
\text { de serviço no contexto da Escola federal. }\end{array}$ \\
\hline Pesquisa Documental & $\begin{array}{l}\text { Documentação do software, relatórios } \\
\text { gerenciais, estrutura organizacional da TI, plano } \\
\text { estratégico de TI. }\end{array}$ \\
\hline
\end{tabular}

Fonte: Quadro organizado pelos autores.

Durante a pesquisa, foi realizado um levantamento criterioso dos pressupostos que embasam a implantação e utilização do Moodle na prática cotidiana dos sujeitos desta pesquisa. Para tanto, foi necessário realizar a coleta dos dados através de questionários com os diferentes sujeitos envolvidos no processo. O questionário, segundo Gil (1999, p. 128), pode ser definido "[...] como a técnica de investigação composta por um número mais ou menos elevado de questões apresentadas por escrito às pessoas, tendo por objetivo o conhecimento de opiniões, crenças, sentimentos, interesses, expectativas, situações vivenciadas, etc.".

No decorrer da pesquisa foi necessário revisar os materiais escritos (projetos de implementação da capacitação de professores, planejamentos de ações docentes, entre outros); conhecer os espaços sócio-político-culturais em que se dá a implantação e implementação do uso das NTIC; realizar ampla revisão teórica sobre concepções dos processos do ensinar e do aprender na instituição de ensino. Na figura abaixo, é possível verificar as fases no desenvolvimento da pesquisa:

Figura 1 - Organização da Pesquisa 


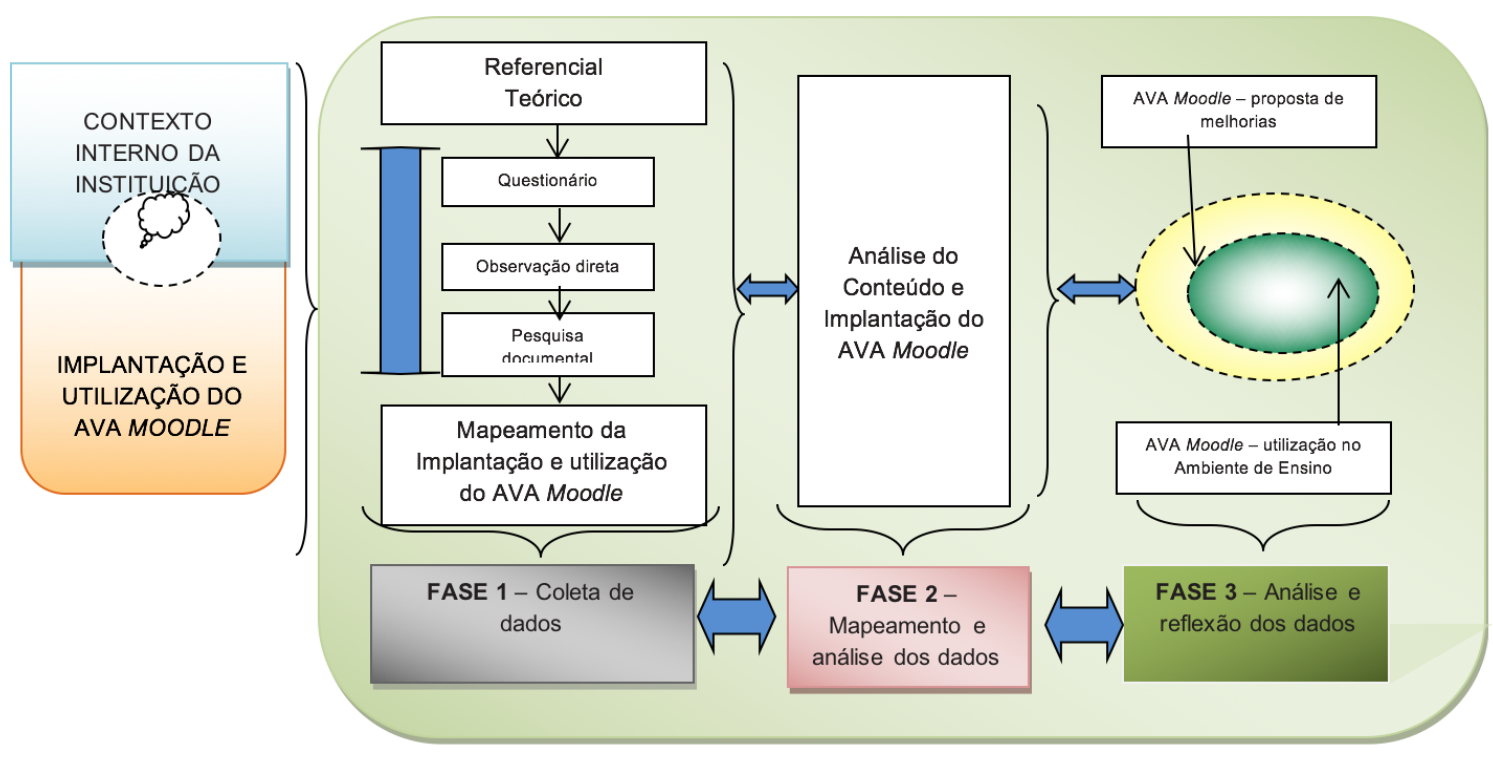

Fonte: Imagem criado pelos autores.

Para melhor compreender as diferentes etapas procurou-se seguir, não de forma linear ou estanque, as três fases (Figura 1), da organização da pesquisa que determinou a estratégia realizada para a coleta de dados visando posterior análise, para o processamento dos elementos coletados na pesquisa. Esse processo propiciou retornar informações relevantes ao material levantado com o questionário e revisão bibliográfica.

\section{Análise da Pesquisa}

\subsection{Moodle e Sua Implantação}

A implementação do Moodle como ferramenta de Ambiente Virtual de Aprendizagem na instituição de Ensino, ocorreu a partir da necessidade dos professores em utilizar ferramentas virtuais de aprendizagem a partir de experiências anteriores em cursos realizados na Pontifícia Universidade Católica do Rio Grande do Sul (PUCRS). A partir das experiências anteriores, conhecimento prévio da ferramenta e a necessidade de aprimorar a construção do conhecimento do novo aluno virtual, os professores solicitaram a sua implantação na escola.

A implantação do Moodle ocorreu desde a sua concepção de forma não obrigatória ao corpo de professores, cabendo ao professor a escolha da aplicação e suas respectivas ferramentas como complemento da sala de aula. A partir da sua aplicação proviniente do professor da respectiva disciplina, é solicitado ao aluno em carater obrigatória a sua utilização. O fato da não obrigatoriedade ao professor, ocorreu pelo fato de muitos professores não estarem familiarizados de forma plena com as ferramentas digitais. Apesar deste fato, gradativamente a partir de pesquisas em documentação institucional foi constatato que com a aposentadoria dos antigos professores e a solicitação dos alunos para a utilização da ferramenta fez com que os professores de forma gradual foram aderindo cada vez mais a utilização do Moodle em sala de aula.

A partir da sua implantação, os professores da instituição obtiveram em caráter não obrigatório, cursos para a utilização da ferramenta e suporte na gestão de suas disciplinas, de acordo com as suas necessidades, a partir do corpo técnico institucional de forma contínua e presencial. Os professores além de obterem as capacitações sempre que solicitado, possuem integralmente o suporte tecnológico de forma presencial para sanar eventuais dúvidas na construção de suas salas virtuais.

Os professores que fazem o uso da ferramenta Moodle como complemento em sala de aula, o fazem de forma complementar, disponibilizando aos alunos vídeos, chat, artigos, lista de 
exercícios, jogos e avaliações on-line. A ferramenta possibilitou que o custo operacional das disciplinas que necessitavam de impressões fosse substituído, quando possível, por material digital.

\subsection{Questionário Aplicado aos Professores}

O questionário foi aplicado aos professores que fazem o uso da ferramenta Moodle por no mínimo 2 anos, em sua maioria com idade superior a 50 anos, com formação mínima de mestrado em sua área específica e dedicação exclusiva ao ensino. As perguntas aplicadas de forma descritiva aos professores foram:

1. Qual a sua opinião como educador na utilização do Moodle como ferramenta de extensão ao ensino?

2. Quais foram as maiores dificuldades na utilização do Moodle? As dificuldades foram superadas?

A aplicação do questionário foi realizado após o estudo do contexto escolar e todo a processo de aplicação do Moodle e suas respectivas etapas de acordo com a Figura 1 de forma complementar não linear, devido ao acesso restrito aos ambientes da instituição que muitas vezes somente foi possível sob supervisão.

\section{Análise e Conclusão dos Dados}

A análise dos dados ocorre a partir da etapa 3, Figura 1, após a realização do questionário e o estudo do contexto e processo de aplicação do Moodle no ambiente escolar. A partir do conceito do construcionismo no uso educacional contemporâneo, e a aplicação do conhecimento construído com base na interação mútua entre o professor e aluno, utilizando o Moodle como meio de comunicação complementar a tradicional sala de aula, foi realizado a análise das respostas do questionário aplicado aos professores envolvidos neste processo. Abaixo segue a análise das respostas atribuídas ao questionário levando em consideração o estudo do ambiente escolar:

1. Qual a sua opinião como educador na utilização do Moodle como ferramenta de extensão ao ensino?

Os professores relatam que o Moodle potencializa as aulas presenciais de forma dinâmica havendo maior interação entre os alunos e o educador, pois o mundo virtual faz parte da natureza do aluno digital. Os professores destacam que com o ambiente virtual é um local seguro para a construção do conhecimento sem propagandas ou elementos impróprios, possibilitando em muitos casos o acompanhamento, orientação bem como o atendimento individualizado a partir de mensagem privadas, que muitas vezes não é realizado em sala de aula, seja por falta de tempo ou vergonha do aluno perante aos demais colegas. A interação, segurança, flexibilidade, acompanhamento e a possibilidade de complementar o conhecimento por meio de ferramentas digitais são os principais fatores destacados na pesquisa, com destaque na redução do número de reprovações após sua aplicação relatados pelos professores.

2. Quais foram as maiores dificuldades na utilização do Moodle? As dificuldades foram superadas? 
Os professores não relataram maiores dificuldades de utilização do ambiente virtual, salientando que os colegas e a área técnica sempre à disposição para eventuais questionamentos foram de fundamental importância para a utilização da ferramenta bem como a sua curva de aprendizagem. Os professores relatam que o Moodle é um aprendizado gradual, que a partir do conhecimento e a troca de informações entre colegas foi possível compreender todas as ferramentas disponíveis na plataforma. Os professores relatam que as maiores dificuldades se encontram na infraestrutura tecnológica da escola, na disponibilidade de computadores e internet para a utilização em ambiente de trabalho e não o ambiente virtual em si. Esta fato ocorre devido que na sala dos professores não há computadores disponíveis para uso simultâneo a todos os professores, havendo a necessidade de acesso ao laboratório de informática com prévio agendamento. As poucas dificuldades relatadas na utilização da ferramenta foram sanadas rapidamente com a maior utilização da ferramenta ou suporte do corpo técnico.

\section{Considerações Finais}

A implantação do Moodle desde a sua concepção de forma não obrigatória ao corpo de professores, cabendo ao professor a escolha da aplicação e suas respectivas ferramentas como complemento da sala de aula, foi de fundamental importância para o seu sucesso, pois não é apenas a ferramenta que contempla o aprendizado e sim a união do professor para com os alunos, a partir do uso de ferramentas educacionais digitais. Outro ponto a ser destacado para o sucesso de sua implantação refere-se aos treinamentos oferecidos bem como o permanente suporte da equipe técnica e pedagógica, a partir da construção do ambiente estendendo-se ao apoio pedagógico em sua utilização.

A partir da construção constante do ambiente e sua inserção em sala de aula de forma gradual, fez com que o aluno aceitasse a sua utilização sem quaisquer barreiras, a partir deste ponto, o próprio aluno solicitava ao professor a inserção de materiais interativos como um roteiro de estudos no decorrer do ano. A partir desta interação, fez com que o aluno se tornasse o protagonista da construção do seu conhecimento e não mais um simples espectador, pois o ambiente proporcionou não somente a interação, mas a ligação entre o mundo analógico, no qual o professor vivenciou durante a sua formação com este "novo" complemento de ensino e aprendizagem que faz parte da genética do aluno digital.

\section{Referências}

BRITO, DÉBORA - Governo lança programa para levar internet via satélite a municípios sem conexão. Brasília: 2018. Disponível em: <http://agenciabrasil.ebc.com.br/politica/noticia/2018-03/governo-lancaprograma-para-levar-internet-satelite-municipios-sem-conexao>.Acesso em: 17 jun 2018.

BASSANI, Patrícia Scherer; BEHAR, Patrícia Alejandra. Análise das interações em ambientes virtuais de aprendizagem: uma possibilidade para avaliação da aprendizagem em EAD. RENOTE - Revista Novas Tecnologias na Educação, Porto Alegre: CINTED/UFRGS, v. 4, n. 1, p. 01-10, jul. 2006. Disponível em: . Acesso em: 20 jun. 2018.

CARVALHO NETO, S. Características Para Avaliação de Qualidade em Ambientes Virtuais de Aprendizagem. São Paulo: [s.n.], 2011. Disponível em: <http://www.abed.org.br/congresso2011/cd/193.pdf>. Acesso em: 18 jun 2018.

FONTES, L; Uma Ontologia de Apoio à Participação Efetiva de Alunos em AVAs, Revista Informática na Educação, Porto Alegre:CINTED/UFRGS,v.20 n.3, p. 01-17, dez. 2017. Disponível em:http://seer.ufrgs.br/ index.php/InfEducTeoriaPratica/article/view/79727/47123 Acesso em: 26 Jul 2018.

FREIRE, P. Educação como prática da liberdade. 24a ed. Rio de janeiro, Paz e Terra. 2000. 
FREIRE, P. Pedagogia da autonomia: saberes necessário à prática educativa. São Paulo: Paz e Terra, 2002.

FREIRE, P. Pedagogia da Autonomia: saberes necessários à prática educativa. 43. ed. São Paulo: Paz e Terra, 2011.

GARCIA, P. S.; BIZZO, N. Formação contínua a distância: gestão da aprendizagem e dificuldades dos professores. Cadernos de Pesquisa. São Paulo, v. 43, n. 149, p. 662-681, mai. - ago., 2013.

GIL, ANTÔNIO CARLOS. Métodos e técnicas de pesquisa social. 5. ed. São Paulo: Atlas, 1999.

$\mathrm{KOH}, \mathrm{K} . \mathrm{T}$. et al. Implementation of a values training program in physical education and sport: a follow-up study. Physical Education and Sport Pedagogy. v. 22, n. 2, p. 197-211, 2017.

LÉVI, PIERRE. Cibercultura. São Paulo: Editora 34, 2000.

M. SCHOLL, P. EHRLICH, A. WIESNER-STEINER AND D. EDICH, "The Project TEDS@wildau: TEDS Framework Integration into the Moodle Platform for User-Specific Quality Assurance of Learning Scenarios," 2014 47th Hawaii International Conference on System Sciences (HICSS), Waikoloa, HI, USA USA, 2014, pp. 1935-1945.

MOODLE (2018). In: Moodle: o software de código aberto para aprendizado colaborativo. Disponível em: . Acesso em: 20 jun. 2018.

MOORE, Michael G. Teoria da Distância Transacional. In: KEEGAN, D. - theoretical Principles of Distance Education. London: Routledge, 1993.

MOORE, Michael; KEARSLEY, Greg. Educação a distância: uma visão integrada. São Paulo: - Thomson Learning, 2007

MORAN, José Manuel et al. Novas tecnologias e mediação pedagógica. 6. ed. Campinas: Papirus, 2000.

MOZZAQUATRO, P. M.; MEDINA R. D. Avaliação do Ambiente Virtual de Aprendizagem Moodle sob Diferentes Visões: aspectos a considerar. Revista Novas Tecnologias na Educação (RENOTE). v. 6, n. 1, 2008. Disponível em: <http://seer.ufrgs.br/renote/article/view/14508 >. Acesso em: 18 jun 2018.

PAPERT, SEYMOUR M. Logo: Computadores e Educação. São Paulo, Editora, Brasiliense, 1985 (edição original EUA 1980).

PAPERT, SEYMOUR. A máquina das crianças: repensando a escola na Era da Informática. [Trad. Sandra Costa]. Porto Alegre: Artes Médicas, 1994.

PIAGET, J. A equilibração das estruturas cognitivas. Rio de janeiro: Zahar Editores, 1976.

SANTOS, E. O. (2009). Saberes da docência online: dialogando com a epistemologia da prática e com os saberes dos professores-tutores da UERJ-CEDERJ. Relatório CNPQ, 2009.

SILVA, M., \& Santos, E. O. (2009). Conteúdos de aprendizagem na educação online inspirar-se no hipertexto. Educação \& Linguagem, v. 12, n. 19, p. 124-142, jan.-jun. 2009.

VALENTE, J.A. (1993a). Diferentes Usos do Computador na Educação. Em J.A. Valente (Org.), Computadores e Conhecimento: repensando a educação (pp.1-23). Campinas, SP: Gráfica da UNICAMP.

VYGOTSKY, L.S. A Formação Social da Mente. 6. Ed. São Paulo: Martins Fontes, 1998.

VYGOTSKY, L. S. A formação social da mente: o desenvolvimento dos processos psicológicos superiores. [Trad. José Cipolla Neto et al. 6. ed., São Paulo: Martins Fontes, 2000.

VYGOTSKY, L. S. A formação social da mente. São Paulo: Martins Fontes, 2007 
WALLON, H. As origens do pensamento na criança. São Paulo: Manole. 1989.

Recebido em Setembro de 2018

Aprovado para publicação em Dezembro de 2018

\section{Lucas Plautz Prestes}

Programa de Pós-Graduação em Informática da Educação- Universidade Federal do Rio Grande do Sul UFRGS, Brasil, lucas.plautz.prestes@gmail.com

\section{Andreia Solange Bos}

Programa de Pós-Graduação em Informática na Educação - Universidade Federal do Rio Grande do Sul UFRGS, Brasil, andreia.bos@gmail.com

\section{Paula R. Castro}

Pontificia Universidade Católica do Rio Grande do Sul - PUC-RS, Brasil, paula.r.castro15@gmail.com

\section{Rafael Boneti}

Pontificia Universidade Católica do Rio Grande do Sul - PUC-RS, Brasil, rboneti@gmail.com

\section{Milton A. Zaro}

Programa de Pós-Graduação em Informática na Educação - Universidade Federal do Rio Grande do Sul UFRGS, Brasil, zaro@ufrgs.br

\section{Agradecimentos}

Programa de Pós-Graduação em Informática na Educação (PPGIE) da Universidade Federal do Rio Grande do Sul (UFRGS). CAPES e CNPq pelo apoio financeiro ao Programa. Ao IFRS (Instituto Federal do Rio Grande do Sul)pelo apoio. 


\section{ANEXO 1}

QUESTIONÁRIO: Professores

*CARACTERIZAÇÃO DO(A) RESPONDENTE:

Idade:

Formação:

Tempo de magistério:

Tempo na gestão:

Regime de trabalho: Concursado ( ) Contratado ( ) Celetista ( )

Carga horária de trabalho:

Trabalha em quais redes de ensino?

Período de utilização do Moodle?

\section{*CARACTERIZAÇÃO DO SISTEMA:}

Sistema em análise:

1. Qual a sua opinião como educador na utilização do Moodle como ferramenta de extensão ao ensino no CMPA?

2. Quais foram as maiores dificuldades na utilização do Moodle? As dificuldades foram superadas? 